\title{
Wind energy resources of the South Baltic Sea
}

\author{
Charlotte Hasager ${ }^{1, *}$, Jake Badger ${ }^{1}$, Ferhat Bingöl ${ }^{1}$, Niels-Erik Clausen ${ }^{1}$, Andrea \\ Hahmann $^{1}$, Ioanna Karagali ${ }^{1}$, Merete Badger ${ }^{1}$ Alfredo Peña ${ }^{1}$ \\ ${ }^{1}$ Risø National Laboratory for Sustainable Energy, DTU, Roskilde, Denmark \\ * Corresponding author. Tel: +45 46775014,Fax:+45 46775970,E-mail: cbha@risoe.dtu.dk
}

\begin{abstract}
The wind resources of the South Baltic Sea in the area between latitude 54 and 58 degrees North and longitude 10 to 22 degrees East are quantified from state-of-the-art methods using a combination of long-term and short-term mesoscale modeling output and satellite-based methods. The long-term overall statistics based on the NCEP/NCAR re-analysis dataset will be used in combination with more than one year of real time simulations using the Weather Research and Forecasting (WRF) mesoscale model operated at Risø DTU. The satellite Synthetic Aperture Radar (SAR) ocean wind maps and scatterometer ocean wind maps from QuikSCAT will be used to evaluate the wind resource calculation. The advantage of including SAR wind maps for evaluation is the finer spatial detail. In some regions, the mesoscale model may not fully resolve the windproducing atmospheric structures. The satellites, however, only provides information at $10 \mathrm{~m}$ above sea level, whereas the mesoscale model provide results at several heights.
\end{abstract}

Keywords: Offshore wind, mesoscale model, satellite data

\section{Introduction}

The wind energy resources in the South Baltic Sea are not known in much detail despite the fact that several wind farms are being planned at sea. The existing wind farms are located typically less than $10 \mathrm{~km}$ offshore whereas most new wind farms are planned further offshore, up to $80 \mathrm{~km}$. There are plans to construct more than $12 \mathrm{GW}$ installed wind farm capacity in the South Baltic Sea. The countries Denmark, Sweden and Germany already have installed offshore wind farms whereas Poland, Russia (Kaliningrad), and the Baltic countries have plans to do so. The web-site http://www.4coffshore.com/windfarms/ provides a listing and map of existing and planned offshore wind farms. It is important to know the wind climate in the planning phase of wind farms, as the expected annual energy production will be proportional to the expected financial benefit of the investment.

The European Wind Atlas ${ }^{1}$ covers land areas http://www.windatlas.dk/Europe/Index.htm whereas the corresponding offshore atlas http://www.windatlas.dk/Europe/oceanmap.html covers sea. It is seen that the Baltic Sea is not fully covered. Furthermore, information gained since year 1999, in particular, from satellite Earth observation and from atmospheric mesoscale modeling jointly provides a new opportunity to map the wind resource with higher spatial detail.

The main objective is to provide a new wind atlas for the South Baltic Sea using available satellite images and mesoscale modeling. The results will be evaluated to meteorological data.

The satellite Earth observations used in the South Baltic wind atlas include scatterometer wind vectors from the SeaWinds instrument on-board the QuikSCAT satellite collected from 1999 to 2009 by NASA, and Synthetic Aperture Radar (SAR) data from the Advanced SAR (ASAR) on-board the satellite Envisat collected from 2002 to present by the European Space Agency (ESA).

In the South Baltic Sea a new approach to the numerical wind atlas method ${ }^{2}$ based on mesoscale modeling is used. The mesoscale model used for the South Baltic is the Weather 
Research and Forecasting (WRF) mesoscale model developed jointly by several US agencies. Additional refinement of the results will be with the microscale model Wind Atlas Analysis and Applications Program (WAsP) ${ }^{3}$ developed at Risø DTU. The Weibull distribution scale (A) and shape $(k)$ parameters and energy density are some of the outputs, see ${ }^{1}$.

The results from satellite and mesoscale modeling are compared, as well as comparison to meteorological masts. The project is on-going. It is approximately mid-term in regard to finalizing the wind atlas, thus the proceedings paper presents work in progress. The investigated area is shown in Fig. 1. The project is related to the South Baltic Offshore Wind Energy Regions (OFF.E.R.) project with partners from Sweden, Germany, Poland, Lithuania and Denmark. The area and team is indicated in Fig. 1.

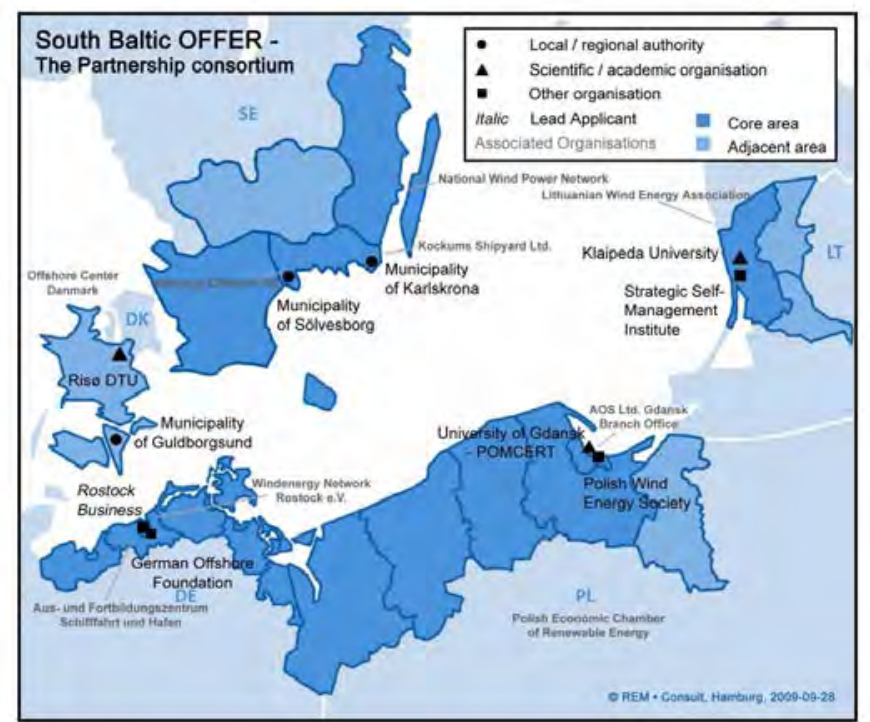

Fig. 1. South Baltic Sea highlighting regions and partners in the South Baltic OFF.E.R. project.

\section{Methodology}

\subsection{Wind profile, meso- and microscale modeling, and satellite remote sensing}

The use of satellite remote sensing is motivated by the fact that only satellites provide spatial observations of ocean winds. Meteorological masts observe winds in the local area in which they are located. Meteorological masts are costly to operate. In some cases access to data is restricted. Thus available offshore meteorological mast data in the South Baltic Sea is limited. The advantage of meteorological masts is that observations typically are collected at several heights, and therefore the vertical wind profile can be quantified. It is well known that the wind profile in its simplest form at low heights is logarithmic and that the wind profile in nonneutral atmospheric stratification and at higher heights deviates from the logarithmic profile ${ }^{4-}$ 8 . For wind resource estimation, the most important level is hub-height where the wind turbines harvest the energy.

Satellite ocean winds are mapped at $10 \mathrm{~m}$ above sea level. It is clear that wind turbine hubheight is higher, say 80 to $100 \mathrm{~m}$. Thus the satellite-based results have to be extrapolated to higher levels. One option is to use WAsP for the vertical extrapolation. Another option is to use the numerical wind atlas. The latter method is applied in the present context. The advantage of mesoscale modeling is that in such models the advection of air is effectively accounted for through modeling over long distances. In contrast, microscale models account for influences only at shorter distances. In enclosed seas such as the Baltic Sea, the surrounding lands are expected to influence winds over long distances. 


\subsection{Satellite techniques}

The techniques of scatterometer and SAR wind retrievals are presented first. Similarities of the two satellites used - QuikSCAT and Envisat - are that they both map any area at specific local times as both satellites are in sun-synchronous polar orbits. For QuikSCAT the local mapping time is around 6 a.m and 6 p.m. while for Envisat it is around 9 a.m. and 9 p.m. in the South Baltic Sea. Both satellites carry microwave radars, i.e. active instruments sending and receiving microwave signals. Microwave radar works day and night and in all weather conditions. The microwaves penetrate cloud, rain and fog. For QuikSCAT though, rain gives rise to problems in case of heavy rain and therefore rain flags are added to the data such that the user can avoid using rain-affected data.

The physical principle of retrieving oceans winds is similar for scatterometer and SAR. The wind over ocean constantly modulates the sea surface creating capillary and short gravity waves. These very short waves are generated near-instantaneously and decay at the same rate, but appear to be in balance at all times to the mean wind speed as observed at $10 \mathrm{~m}$. The Geophysical Model Function (GMF) that describe the relationship between the backscattered normalized radar cross section is found to be non-linearly proportional to the wind speed, as a function on slant range and relative wind direction in regard to the viewing geometry. For further details on ocean wind mapping see references for scatterometer ${ }^{9-11}$ and SAR ${ }^{12-14}$. The nominal accuracy on wind speed is within $2 \mathrm{~m} \mathrm{~s}^{-1}$ for wind speeds between 3 and $25 \mathrm{~m} \mathrm{~s}^{-1}$.

To highlight major differences between scatterometer and SAR the following may be noted: Scatterometer provides medium spatial resolution, around $25 \mathrm{~km}$ by $25 \mathrm{~km}$ grid size whereas SAR provides high spatial resolution, around $1 \mathrm{~km}$ by $1 \mathrm{~km}$ grid size. The resolutions here refer to the final wind results (not the raw sampling which has much higher spatial resolution).

The swath of QuikSCAT was very wide, $1800 \mathrm{~km}$, and this means that most of the globe was mapped twice per day for the 10 years of active observations. This results in roughly 7300 individual ocean wind maps in the South Baltic Sea. The archive is freely available, e.g. from Remote Sensing Systems (http://www.remss.com/qscat/) as so-called level 3 products. This means as gridded geo-coded products of wind speed and wind direction.

In contrast, Envisat ASAR has a swath of $400 \mathrm{~km}$ in the so-called wide swath mode (WSM). The sampling in WSM provides a possibility of mapping any location in the South Baltic around 10 times per month. From simple calculation the data could amount to roughly 1000 samples everywhere on the globe. However, Envisat ASAR was and is not always mapping, as the mapping is based 'on demand', typical for science or for commercial activity, and also, the on-board data storage and downlink cannot handle continued operation. The archive at ESA (http://earth.esa.int/EOLi) provide gateway to check the actual data availability. In the present work around 3000 WSM wind maps are used, meaning roughly 400 available samples in each grid cell. For SAR-based wind mapping the raw data are retrieved by Risø DTU and processed into wind maps using the Johns Hopkins University Applied Physics Laboratory software ANSWRS ${ }^{15}$.

Finally, an important difference between scatterometer and SAR is that while scatterometer observes the ocean surface from several angles using multiple antennae or rotating antenna (as for QuikSCAT), SAR only views the surface from one direction. This basic difference means that only scatterometer provides both wind speed and direction through the GMF. In order to map wind speed from SAR it is necessary first to estimate the wind direction, and use this $a$ 
priori information in the GMF. In our case we use the wind direction from the global atmospheric model by the US Navy, the so-called NOGAPS model. Further detail in ${ }^{12}$.

\subsection{Statistical-dynamical downscaling}

The long-term overall statistics based on the NCEP/NCAR re-analysis dataset 1980-2009 will be used in combination with nearly two years of real time simulations using the WRF mesoscale model operated at Risø DTU. The usual procedure at Risø DTU for calculating wind resource with the numerical wind atlas method involves, as a first step, the definition of a set of wind classes. The set of wind classes represent the different wind conditions (wind speed, direction and atmospheric stability) defined from long term, large scale atmospheric reanalysis datasets.

The wind classes are based on geostrophic wind and potential temperature at $0,1500,3000$, $5500 \mathrm{~m}$ above sea level. The wind classes are defined by the distribution of wind speed, direction and stability at one point. For the South Baltic wind atlas the area of interest is large. It is therefore of interest to see how well wind classes defined at one point manages to represent the large scale climate over this large area. There are two issues: 1) do wind classes represent the large scale wind climate well over the entire region of interest; 2) to what extent can a single wind class describe the wind in the region at any given time.

The WRF model is triple nested to the inner domain over Denmark with a $2 \mathrm{~km}$ by $2 \mathrm{~km}$ grid resolution for the weather forecasts, but the outer grid at an $18 \mathrm{~km}$ by $18 \mathrm{~km}$ grid covers most of the South Baltic. The weather forecasts plus some additional simulations at higher resolution will be used as basis in the statistical-dynamical downscaling.

\section{Results}

\subsection{Satellite results}

Results from the study area using QuikSCAT are shown in Fig. 2. The results are based on all available ocean wind maps from RSS without rain-flag from 10 years, 1999 to 2009. The results are maps of the Weibull A and k parameters. Weibull A is seen to vary from 8.0 to 8.5 $\mathrm{m} \mathrm{s}^{-1}$ in the South Baltic Sea, and Weibull k is seen to vary from 1.9 to 2.3. Near the coastlines the white area indicates that data are not available.
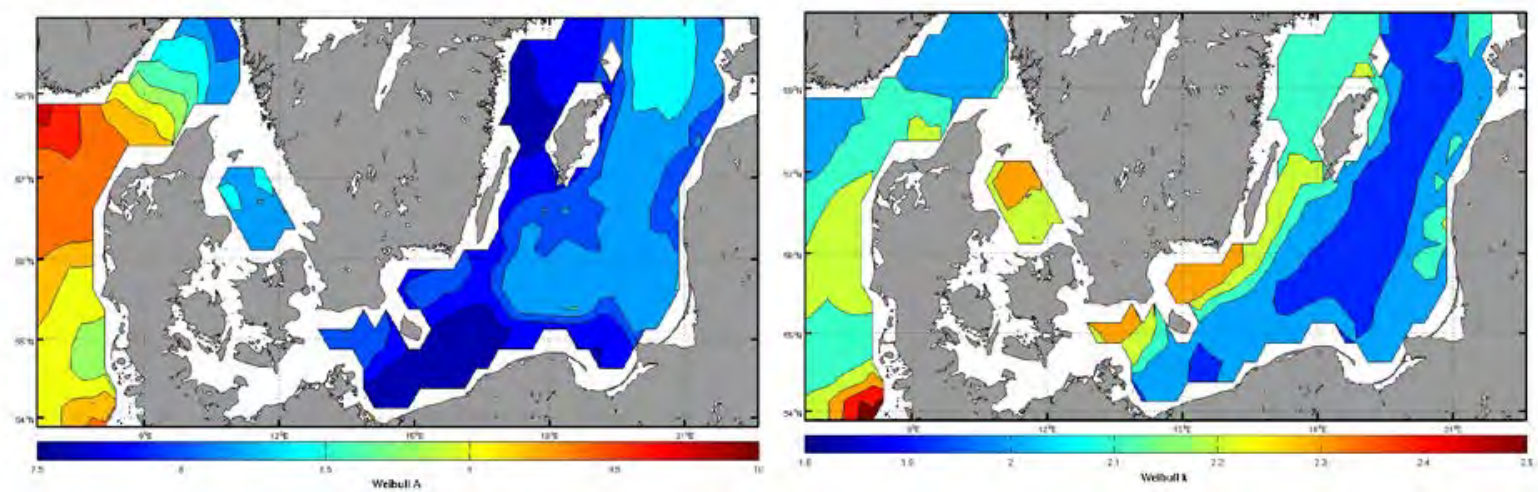

Fig. 2 Weibull A ranging from 7.5 (blue) to 10.0 (red) $\mathrm{m} \mathrm{s}^{-1}$ and Weibull $k$ ranging from 1.8 (blue) to 2.5 (red) in the South Baltic and Danish Seas observed from 10 years of QuikSCAT ocean wind maps. Domain size is $7^{\circ}$ to $22^{\circ}$ East and $53^{\circ}$ to $59^{\circ}$ North.

Results from the study area using Envisat ASAR are shown in Fig. 3. The upper panel shows the number of wind maps, the middle panel the mean wind speed, and the lower panel the 
energy density. In most of the area there are more than 400 samples. The mean wind speed varies from around $5 \mathrm{~m} \mathrm{~s}^{-1}$ to nearly $11 \mathrm{~m} \mathrm{~s}^{-1}$. Finally, the energy density varies from 400 to nearly $1200 \mathrm{~W} \mathrm{~m}^{-2}$. In particular near the coastlines, the energy density is seen to be low. High energy density is found in the open sea.

\subsection{Wind class results}

Four sets of wind classes were defined, all based on the large scale conditions at $16.25 \mathrm{E}$ 56.25N. The sets, named SB1, SB2, SB3, SB4, contain 134, 84, 84, 36 wind classes respectively, see Fig. 4 . Sets SB1, SB2, SB4 differ in that a different number of wind classes are allowed for each direction sector (14, 7, 3 respectively) but in each sector the wind speed range of each wind class varies so as to get obtain wind classes with approximately equal frequency of occurrence. Set SB3 uses 7 wind classes per sector, but the wind speed range is fixed and this the frequency of each wind classes varies within each sector.

The first question is, how well do the wind classes represent the large-scale wind climate over the South Baltic. This is answer is: The 134 wind classes of set SB1 capture the wind power in the large scale climate quite accurately with only a small error of less than $3 \%$ in the mean of the wind cubed. Whereas the 36 wind classes of set SB4 do more poorly, with an error in the region of $14 \%$ in the mean of the wind cubed. Wind classes sets SB2 and SB3 give an error in the region of $5 \%$ on the mean of the wind cubed.

The second question concerns to what extent it can be expected that a single wind class, at any given time is influencing the area of interest. The probability of a single wind class acting over a region rapidly drops off when moving away from $16.25 \mathrm{E} 56.25 \mathrm{~N}$. We may conclude that occasions where the same wind class influences large parts of the region of interest happen very rarely. By selecting periods where the wind classes are persistent the probability of locations experiencing the wind class is increased. However, it is not thought that persistency filtering is sufficiently powerful for the South Baltic domain. In conclusion, the variability means that an approach where several wind classes acting more locally, as opposed to acting over the whole domain, will have to be defined and used for the downscaling.

\section{Discussion}

Satellite wind maps from QuikSCAT provide twice daily 10 year results at $25 \mathrm{~km}$ by $25 \mathrm{~km}$ resolution. The WRF statistical-dynamical downscaling will provide 30 year results at $5 \mathrm{~km}$ by $5 \mathrm{~km}$ resolution. Envisat ASAR provides results at $1 \mathrm{~km}$ by $1 \mathrm{~km}$ resolution. The challenge of using different sources of information is the reliability of each. Comparisons between SAR and three meteorological masts in the North Sea ${ }^{16}$ show good agreement, less than $5 \%$ error on mean wind speed, Weibull A and $\mathrm{k}$. Comparisons between SAR and meteorological masts in the South Baltic Sea show similar agreement for mean wind speed, but less good agreement for Weibull A and $\mathrm{k}^{17}$. Mesoscale model results typically range between 10 to $15 \%$ uncertainty. Thus combining satellite wind maps and mesoscale modeling is expected to provide an accurate wind atlas for the South Baltic Sea. 


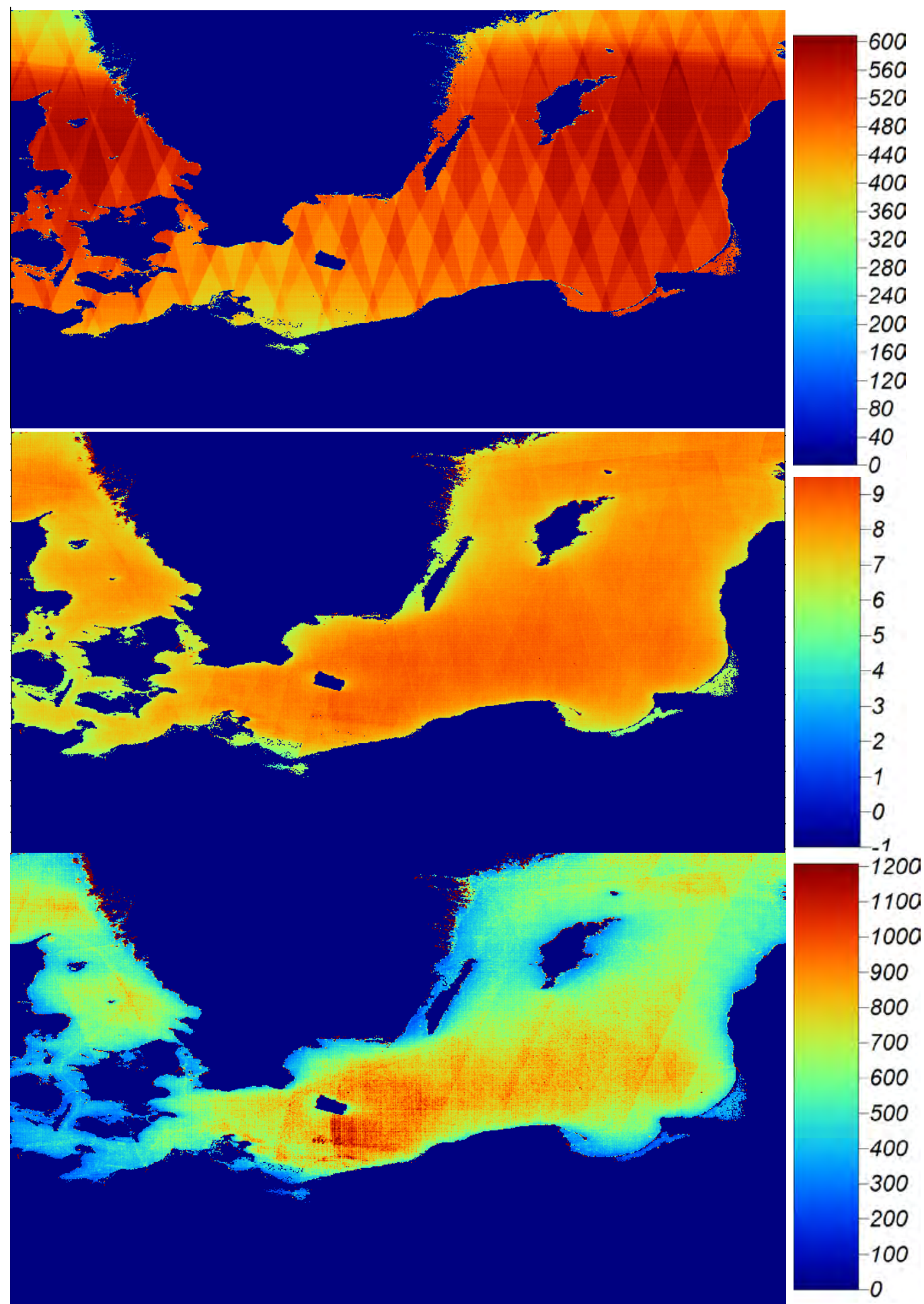

Fig. 3 Envisat ASAR wind maps: (Top) Number of wind speed maps use; (Middle)Mean wind speed in $\mathrm{m} \mathrm{s}^{-1}$; (Bottom) Wind energy density in $\mathrm{W} \mathrm{m}^{-2}$ for the South Baltic Sea. Domain size is $10^{\circ}$ to $22^{\circ}$ East and $52^{\circ}$ to $59^{\circ}$ North. 
(a)

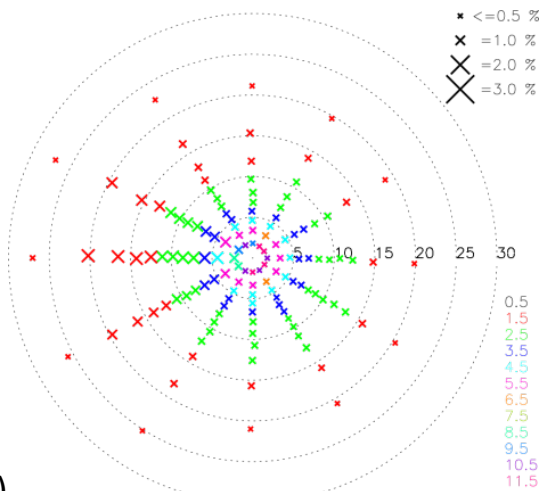

(c) (b)

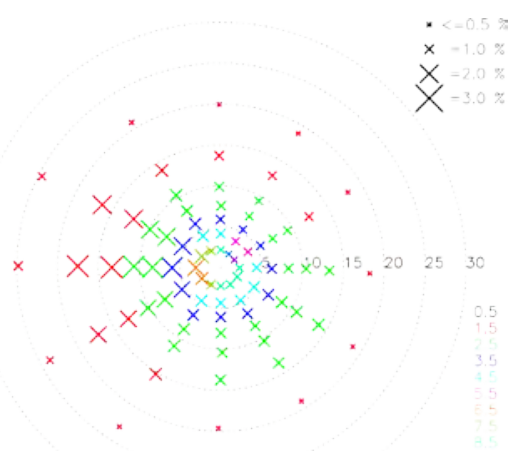

(d)

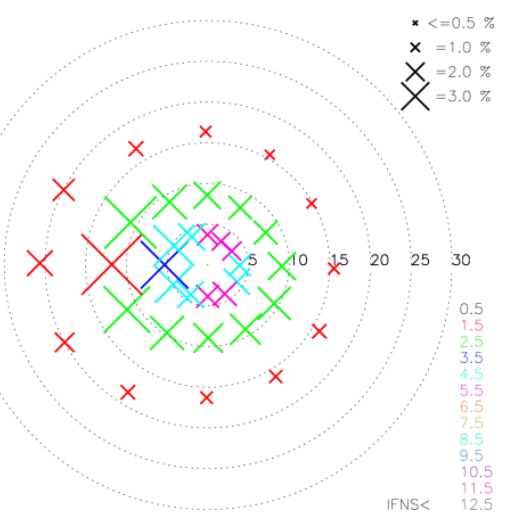

Fig. 4 Four sets of wind classes (a) SB1, (b) SB2, (c) SB3 and (d) SB4. Each cross represents a forcing wind speed (distance from the centre of the diagram) and direction. The speed scale is in $\mathrm{m} \mathrm{s}^{-1}$. The colours indicate the inverse Froude number squared (IFNS).

\section{Conclusion}

The wind atlas for the South Baltic Sea is in progress using satellite remote sensing and mesoscale modeling. The final results will be compared to available meteorological data to estimate the uncertainty of the results. The analysis will be completed in Spring 2011.

\section{Acknowledgements}

We acknowledge support from South Baltic OFF.E.R and satellite data from ESA and RSS.

\section{References}

[1] I. Troen,; E. L.Petersen, European Wind Atlas; Risø National Laboratory: Roskilde, 1989.

[2] H.Frank; O. Rathmann; N. Mortensen; L. Landberg The Numerical Wind Atlas, the KAMM/WAsP Method;Risø-R-1252(EN); Roskilde, Denmark, 2001.

[3] N. Mortensen; D. N. Heathfield; L. Landberg; O. Rathmann; I. Troen; E.L.Petersen Wind Atlas Analysis and Wind Atlas Analysis and Application program:WAsP 7.0 Help Facility;ISBN 87-550-2667-2; Risø National Laboratory: Roskilde, 2000.

[4] A. Sathe; S.E. Gryning, A. Peña, Comparison of the Atmospheric Stability and Wind Profiles at two Wind Farm Sites over a long marine fetch in the North Sea. Wind Energy 2010, (in press).

[5] A. Peña; C.B. Hasager, S.E. Gryning; M.Courtney; I. Antoniou; T. Mikkelsen. Offshore wind profiling using light detection and ranging measurements. Wind Energy 2009, 12, 105-124. 
[6] C.B.Hasager; A. Peña; M.B.Christiansen; P.Astrup;M.Nielsen;F.Monaldo;D.Thompson; P.Nielsen.Remote sensing observation used in offshore wind energy. IEEE Journal of Selected Topics in Applied Earth Observations and Remote Sensing 2008, 1 (1), 67-79.

[7] A.Peña; S.E.Gryning. Charnock's roughness length model and non-dimensional wind profiles over the sea. Boundary-Layer Meteorology 2008, 128, 191-203.

[8] A.Peña; S.E.Gryning; C.B.Hasager. Measurements and Modelling of the Wind Speed Profile in the Marine Atmospheric Boundary Layer. Boundary-Layer Meteorology 2008, 129 (3), 479-495.

[9] W.T.Liu;W.Tang Equivalent neutral wind; National Aeronautics and Space Administration, Jet Propulsion Laboratory, California Institute of Technology, National Technical Information Service, distributor: 1996.

[10]H.Hersbach; A.Stoffelen;S.de Haan.An improved C-band scatterometer ocean geophysical model function:CMOD5. J. Geophysical Research 2007, 112 (C03006).

[11] A.Stoffelen; D.L.T.Anderson. Wind retrieval and ERS-1 scatterometer radar backscatter measurements. Advance Space Research 1993, 13, 53-60.

[12]M.B.Christiansen;C.B.Hasager;D.R.Thompson;F.Monaldo.Ocean winds from synthetic aperture radar. In Ocean remote Sensing: Recent Techniques and Applications., Niclos, R., Caselles, V., Eds.; Research Singpost Editorial: 2008; pp 31-54.

[13]R.C.Beal; G.S.Young;F. Monaldo; D.R.Thompson; N.S.Winstead; C.A.Schott High resolution wind monitoring with Wide Swath SAR: A user's guide; U.S. Department of Commerce: Washington, DC, 2005.pp. 1-155.

[14]F.Monaldo;D.R.Thompson;N.S.Winstead;W.Pichel;P.Clemente-Colón;M.B.Christiansen. Ocean wind field mapping from synthetic aperture radar and its application to research and applied problems. Johns Hopkins Apl. Tech. Dig. 2005, 26, 102-113.

[15]F.Monaldo. The Alaska SAR demonstration and near-real-time synthetic aperture radar winds. John Hopkins APL Technical Digest 2000, 21, 75-79.

[16] M.Badger; J.Badger;M.Nielsen;C.B.Hasager;A.PeñaWind class sampling of satellite SAR imagery for offshore wind resource mapping. J. Applied Meteorology and Climatology 2010, 49,12,2474-2491.

[17]Hasager, C. B.; Badger, M.; Peña, A.; Larsén, X. G. SAR-Based Wind Resource Statistics in the Baltic Sea. Remote Sensing 2011, 3,1,117-144. 